Postprint version. Original publication in:

Ecological Entomology (2005) 30:299-306

doi: http://dx.doi.org/10.1111/j.0307-6946.2005.00706.x

\title{
Selection of large host plants for oviposition by a monophagous leaf beetle: nutritional quality or enemy-free space?
}

\author{
Annette Heisswolf, Elisabeth Obermaier, Hans Joachim Poethke
}

Field Station Fabrikschleichach, University of Würzburg, Glashüttenstrasse 5, D-96181 Rauhenebrach

\begin{abstract}
Oviposition site selection is crucial for the reproductive success of herbivorous insects. According to the preference-performance hypothesis, females should oviposit on host plants that enhance the performance of their offspring. More specifically, the plant vigor hypothesis predicts that females should prefer large and vigorously growing host plants for oviposition and that larvae should perform best on these plants.

The present study examined whether females of the monophagous leaf beetle Cassida canaliculata Laich. (Coleoptera: Chrysomelidae) prefer to oviposit on large host plant individuals of the meadow clary and whether large host plants are of higher nutritional quality than small host plants. Subsequently, it was tested whether the female preference correlates with offspring performance and survival.

In the field, females preferred large host plant individuals for oviposition and host plant quality, i.e. leaf nitrogen content, was significantly higher in leaves of large than of small host plants. In the laboratory, larval development time was shorter on leaves of large host plant individuals than on small host plant individuals, but this could not be shown in the field. However, a predator-exclusion experiment in the field resulted in a higher survival of larvae on large host plants than on small host plants when all predators had free access to the plants. On caged host plants there was no difference in survival of larvae between plant size categories.

It is concluded that females of $C$. canaliculata select oviposition sites that enhance both performance and survival of their offspring, which meets the predictions of the plant vigor hypothesis.
\end{abstract}

Keywords. Chrysomelidae, leaf nitrogen content, plant vigour, predator-exclusion, preference-performance hypothesis, tortoise beetle, Salvia pratensis.

\section{INTRODUCTION}

In phytophagous insects, like leaf beetles, oviposition site selection is crucial for the successful development of larvae (Singer, 1986; Mayhew, 1997). In species that complete their whole development on a single host plant, host plant selection is even more 
essential (Singer, 1986; Craig et al., 1989). Optimal oviposition theory (Jaenike, 1978) predicts that oviposition preference should correlate with host plant suitability for offspring development as females are assumed to maximize their fitness by ovipositing on high quality hosts (Awmack \& Leather, 2002). This concept is often referred to as 'preference-performance hypothesis' (Jaenike, 1978). Oviposition site selection can be influenced by the quality or quantity of the host plant (Mattson, 1980; Strong et al., 1984; Obermaier \& Zwölfer, 1999). In this context, Price (1991) developed the 'plant vigor hypothesis', which is a special case of the preference-performance hypothesis. It predicts that vigorous plants that grow faster and ultimately reach a larger than average size should be preferred by the herbivore. Both plant biomass and nutritive quality, which are key factors for the development of herbivorous insects (McNeill \& Southwood, 1978; Mattson, 1980; Strong et al., 1984; Obermaier \& Zwölfer, 1999), are supposed to be higher in vigorous plants than in other plants. The most important nutrient required by phytophagous insects is protein, which is usually the limiting factor for optimal growth (McNeill \& Southwood, 1978; Mattson, 1980; Strong et al., 1984; Crawley, 1989; White, 1993; Bernays \& Chapman, 1994).

Positive correlations between oviposition site preference and offspring performance have been shown for different species (Craig et al., 1989; Kouki, 1993; Preszler \& Price, 1995; Howlett et al., 2001; Craig \& Ohgushi, 2002; De Bruyn et al., 2002; Forister, 2004). However, many examples can also be found in the literature where females did not seem to prefer oviposition sites that would be best for the performance of their offspring (Rausher, 1979; Courtney \& Kibota, 1990; Valladares \& Lawton, 1991; Underwood, 1994; Berdegué et al., 1998; Fritz et al., 2000; Scheirs et al., 2000, 2004; Faria \& Fernandes, 2001; Harris et al., 2001; Shiojiri \& Takabayashi, 2003; van Nouhuys et al., 2003). Thus, Scheirs \& De Bruyn (2002) suggested integrating the two concepts of optimal foraging and optimal oviposition in plantinsect research. Optimal foraging theory predicts that phytophagous adults should prefer to feed on those hosts that give the highest adult performance (Stephens \& Krebs, 1986). However, optimal adult and optimal offspring resources may be separated in space, and search-time constraints may therefore prevent the optimization of both strategies (Nylin \& Janz, 1996; Krebs \& Davies, 1997). Other approaches include the influence of higher trophic levels on oviposition site choice, as nutritionally inferior host plants may be chosen when they provide enemy-free space for the offspring (Hawkins et al., 1993; Björkman et al., 1997; Ballabeni et al., 2001; Obermaier et al., 2001; Singer \& Stireman III, 2003).

This study tested the preference-performance predictions of the plant vigor hypothesis (Price, 1991) in the monophagous leaf beetle Cassida canaliculata Laich. which feeds exclusively on meadow clary (Salvia pratensis L.). It was investigated whether 
offspring (i.e. larval) performance correlates with the oviposition site preference of the female beetles. Four questions were asked: (1) Do females prefer large-sized host plants for oviposition? (2) Do large host plants provide a higher nutritional quality, i.e. a higher leaf nitrogen content than small ones? (3) Do larvae perform better on large than on small host plants? (4) Do larvae have a higher chance of survival on larger than on small host plant individuals? The first question was addressed in a field study, questions 2 and 3 were investigated in a developmental study in the laboratory, while the last question was examined in a field experiment.

\section{MATERIAL AND MethodS}

\section{Species under study}

The monophagous tortoise beetle Cassida canaliculata Laich. belongs to the family of the leaf beetles (Coleoptera: Chrysomelidae, subfamily Cassidinae). With a body size of 9-11 mm C. canaliculata is the largest German tortoise beetle (Trautner et al., 1989). Within Germany, the species is quite rare and found only on warm slopes in the southern part of the country. It is monophagous on Salvia pratensis L. (Lamiales: Lamiaceae), the meadow clary, on which all developmental stages can be found. The eggs are deposited in small clutches ( $8 \pm 4$ eggs per clutch) on the underside of the leaves and are covered with a secretion layer. Oviposition takes place from April to late June The host plant, S. pratensis, is very common in southern Germany. It is a perennial herb with a ground rosette that grows on dry meadows and field edges. The rosettes start to grow in late March and flowering begins in May (Schmeil \& Fitschen, 1996).

\section{Plant size categories}

The host plants were divided into two size categories: large and small plants. Large plants were defined as plants that had an average ground rosette diameter of more than $20 \mathrm{~cm}$ and at least four vegetative cones. The category of small plants consisted of those plants that had an average ground rosette diameter of less than $10 \mathrm{~cm}$ and only one vegetative cone. This categorization was applied both to plants used in the laboratory as well as in the field study.

\section{Oviposition site preference in the field}

Adult oviposition site preference depending on the size of the host plant was studied at a mesoxerophytic grassland site $\left(5000 \mathrm{~m}^{2}\right)$ in the Hohe Wann nature reserve in Northern Bavaria, Germany $\left(50^{\circ} 03^{\prime} \mathrm{N}, 10^{\circ} 35^{\prime} \mathrm{E}\right)$. Within this site a $16 \times 16 \mathrm{~m}^{2}$ 
grid-plot of 64 subplots $\left(2 \times 2 \mathrm{~m}^{2}\right)$ was created. In 12 randomly selected subplots host plant size, i.e. average rosette diameter, and oviposition incidence were recorded for all 650 S. pratensis plants growing in these patches.

\section{Larval development in the laboratory}

For the laboratory experiments with larvae of $C$. canaliculata nine female/male pairs of field-collected adults were kept in separate boxes in a climatic chamber at a day temperature of $20 \mathrm{C}$ and night temperature of $16 \mathrm{C}$ and a LD 16:8 h photoperiod. Egg clutches were isolated and inspected daily for hatching larvae. The experiment started when at least $40 \mathrm{~L} 1$ larvae (not older than $24 \mathrm{~h}$ ) were available. The larvae were randomly distributed into two treatment groups. In the first group ('L group') 20 larvae were reared on leaves of large plants of S. pratensis; in the second group ('S group') another 20 larvae were reared on leaves of small plants. The larvae were kept singly in plastic containers and were placed onto a single leaf. The leaves used for the feeding experiments were harvested at a mesoxerophytic grassland site in the Hohe Wann nature reserve where the leaf beetles occur naturally. Leaves were always collected at the same time of the day because of possible diurnal rhythms in the level of nitrogen. Inside the plastic boxes the leaves had a permanent water supply. After 4 days the leaves were replaced by new ones. For both treatment groups larval development time, pupal development time, and pupal weight were recorded. Leaf nitrogen content of the remaining leaf material was measured as a surrogate for host plant quality, as leaf nitrogen content is an adequate measure for protein content and as $S$. pratensis contains hardly any secondary plant compounds (Frohne \& Jensen, 1985). The leaf material was dried at $70^{\circ} \mathrm{C}$ for $48 \mathrm{~h}$, ground in a mill (Retsch $\mathrm{GmbH} \& \mathrm{Co} . \mathrm{KG}$, Haan, Germany), and analyzed for per cent leaf nitrogen content in an elemental CHN analyzer (W. C. Heraeus Elemental Analysis, Hanau, Germany).

\section{Larval survival in the field}

The predator-exclusion experiment was conducted at a mesoxerophytic grassland site $\left(6800 \mathrm{~m}^{2}\right)$ in the Hohe Wann nature reserve (see above for details). Sixty random points were generated on an aerial photo of the grassland site via the spatial analyst of the ArcView GIS software package (ESRI, Redlands, California). In the field, the random points were located with a portable GPS, and by the nearest-neighbor method 30 large and 30 small plants of $S$. pratensis were selected. This method may lead to a bias, as choosing plants by the nearest-neighbor method will tend to preferentially select plants growing in low densities over those growing in high densities. However, such a bias seemed negligible compared with the higher effort of a truly random sampling method. On each plant six L1 larvae were placed on the underside of one leaf. Large 
and small plants were each divided into three treatment groups. The first group (No Cage) received no treatment. All predators and parasitoids had free access to the larvae on the plants. In the two other groups, each plant was surrounded by a cage of $30 \times$ $30 \times 40 \mathrm{~cm}^{3}$ size. The cages consisted of a wooden frame that was covered with gauze (about $0.5 \mathrm{~mm}$ mesh-width). In the second treatment group (Open Cage) the cage was not completely closed: the top of the cage and a stripe of $5 \mathrm{~cm}$ width at the bottom of the cage were left open. This treatment group served as a control for existing cage effects due to changed microclimate within the cage. In the third treatment group (Closed Cage) the whole cage was covered with gauze to exclude all predators and parasitoids. The inner side of the bottom frame of the cages in the Closed Cage group was covered with a ring of glue to record larvae that tried to leave the plants. In all treatment groups the larvae were counted each second day until pupation. From these data, larval survival and larval development time could be determined.

\section{Statistics}

Adult oviposition site preference was tested with a logistic regression model. In order to evaluate the goodness-of-fit of the regression model the coefficient of determination $R^{2}$ after Nagelkerke (1991) was considered $\left(R_{\text {Nagelkerke }}^{2}\right)$. ROC plots (receiver operating characteristics), i.e. the area under the resulting curve ('area under curve' $=A U C$ ), were used to determine the classification accuracy of the model (Hanley \& McNeil, 1982, 1983; Zweig \& Campbell, 1993). Developmental data were tested for normal distribution using the Kolmogorov-Smirnov test. $t$-tests and Mann-Whitney $U$-tests were used to compare the data on larval development between the two plant size groups. The proportion of larvae surviving to pupation were compared with binomial Generalized Linear Models (GLMs) and ANOVA. All statistical procedures were calculated with the software packages R 1.9.1 (R Development Core Team, 2004) and SPSS 12.0.2 (SPSS Inc., 2004).

\section{RESULTS}

\section{Oviposition site preference in the field}

The probability of oviposition increased highly significantly with the size of the host plant individuals (coefficient $=0.146, R_{\text {Nagelkerke }}^{2}=0.109, P<0.001, A U C=$ $0.671, n=650$, Figure 1). 


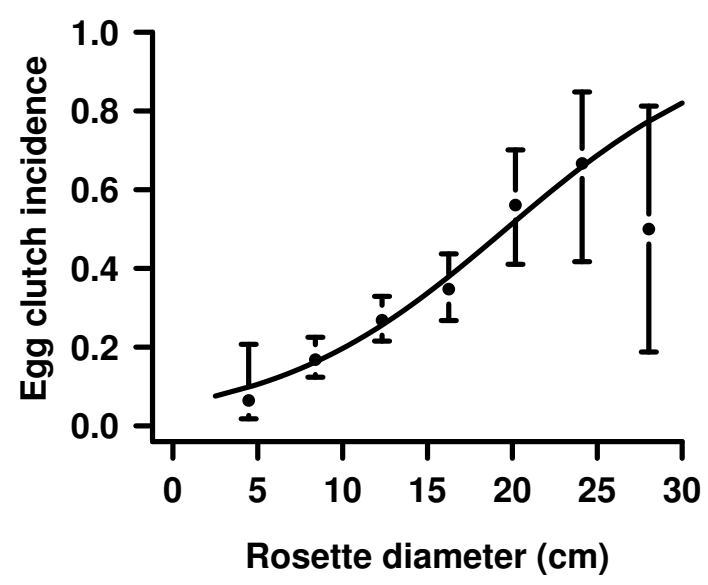

Figure 1: Oviposition site preference in Cassida canaliculata depending on host plant size. Plotted are the mean $\pm 95 \%$ CI of the egg clutch incidences in rosette diameter classes of $4 \mathrm{~cm}$ (circles with bars) and the predicted probability of egg clutch incidence (line) calculated by the logistic regression model, $n=650$ plants.

\section{Larval development in the laboratory}

Larval development time was significantly shorter in the group of larvae reared on leaves of large plants (L group) compared with the larvae reared on leaves of small plants (S group) $(t=6.559, P<0.001, n=38)$. Pupal development time was, however, significantly longer in the $\mathrm{L}$ group than in the $\mathrm{S}$ group $(U=84.50, P=0.004, n=$ 38). Total development time was again significantly shorter in the L group than in the $\mathrm{S}$ group $(t=3.830, P<0.001, n=38)$. There was no significant difference in pupal weight between the two treatment groups $(t=-1.747, P=n . s ., n=38)$. Per cent leaf nitrogen content was significantly higher in leaves of large plants than in leaves of small plants $(t=-9.455, P<0.001, n=38)$. A summary of the results on larval development can be found in Table 1 .

Table 1: Larval development of Cassida canaliculata in the laboratory. Development time, pupal weight, and leaf nitrogen content are shown. One group of larvae was reared on leaves of large plants $(r>20$ $\mathrm{cm})$, the other group on leaves of small plants $(r<10 \mathrm{~cm}) . n=19$ larvae in both treatment groups. Mean values $\pm \mathrm{SD}$ and $P$-values of the $t$-test $(t)$ or Mann-Whitney $U$-test $(U)$ are given.

\begin{tabular}{lllrl}
\hline Parameter & Large plants & Small plants & $\boldsymbol{P}$-value & \\
\hline Larval development time (days) & $25.0 \pm 0.9$ & $27.5 \pm 1.4$ & $<0.001$ & $(t)$ \\
Pupal development time (days) & $11.2 \pm 0.7$ & $10.4 \pm 0.7$ & 0.004 & $(U)$ \\
Total development time (days) & $36.2 \pm 1.3$ & $37.9 \pm 1.4$ & $<0.001$ & $(t)$ \\
Pupal weight (mg) & $49.9 \pm 5.4$ & $47.2 \pm 4.1$ & 0.089 & $(t)$ \\
Leaf nitrogen content (\%) & $3.10 \pm 0.22$ & $2.48 \pm 0.19$ & $<0.001$ & $(t)$ \\
\hline
\end{tabular}


Table 2: Larval development of Cassida canaliculata in the field. Development time is shown for large and small host plants in the three treatment groups No Cage, Open Cage, and Closed Cage (A detailed description of the three cage groups is given in the text.) Mean values $\pm \mathrm{SD}$, number of larvae, and $P$-values of the Mann-Whitney $U$-test are given.

\begin{tabular}{llllll}
\hline & \multicolumn{2}{l}{ Larval development time (days) } & & \\
\cline { 2 - 6 } Treatment & Large plants & $n$ & Small plants & $n$ & $\boldsymbol{P}$-value \\
\hline No Cage & $43.8 \pm 4.3$ & 12 & $45.0 \pm 1.4$ & 2 & 0.713 \\
Open Cage & $47.6 \pm 3.7$ & 11 & $46.6 \pm 4.8$ & 7 & 0.613 \\
Closed Cage & $44.9 \pm 2.5$ & 16 & $43.5 \pm 2.9$ & 17 & 0.141 \\
\hline
\end{tabular}

\section{Larval survival in the field}

In the No Cage treatment group a significantly higher proportion of larvae survived to pupation on large plants than on small plants $(z=2.513, P=0.012, n=20)$. In the group with 'open cages' there was no significant difference between the survival of larvae on large or small plants $(z=1.237, P=n . s ., n=20)$. In the Closed Cage treatment group also, the survival of larvae did not differ between the plant size groups $(z=-0.204, P=n . s ., n=20)$. Comparing the survival of larvae within each plant size group, there was no significant difference between the No Cage and the Open Cage group on small plants $(z=1.630, P=n . s ., n=20)$. However, there was a significant difference both between the No Cage and the Closed Cage group $(z=3.151, P=$ $0.002, n=20)$ as well as between the Open Cage and the Closed Cage group $(z=$ $-2.220, P=0.026, n=20$ ). On large plants there was no difference in larval survival between the three cage groups (ANOVA: $F_{d f}=0.5039, P=n . s ., n=30$ ). A summary of the data can be found in Figure 2. Larval development time in the field did not differ significantly between the two host plant size groups $(t=-0.982, P=n . s ., n=$ $65)$. The detailed larval development times of the three treatment groups are given in Table 2 .

\section{DisCUSSION}

Although there are many reports of poor correlations between female oviposition site preference and offspring performance (reviewed by Mayhew, 1997), a strong oviposition-preference-offspring-performance relationship is still the basic assumption of most models describing oviposition site choice (Jaenike, 1978; Mayhew, 1997). Thus it is indispensable to collect more data on oviposition site choice and its consequences for adult and offspring performance. The plant vigor hypothesis (Price, 1991) - as a special case of the preference-performance hypothesis - predicts that females should prefer vigorously growing host plant individuals for oviposition, which should consequently enhance the performance of their larvae on those host plants. 


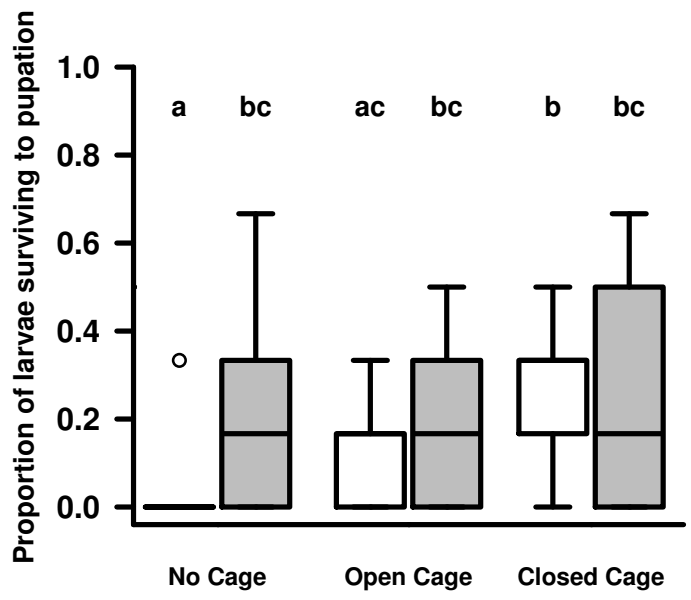

Figure 2: Larval survival of Cassida canaliculata on large and small host plant individuals in the field. A box-and-whisker plot of the proportion of larvae surviving to pupation in the three treatment groups No Cage, Open Cage, and Closed Cage is shown. (A detailed description of the three cage groups is given in the text.) White boxes represent small plants, grey boxes represent large plants. Each treatment group consists of $n_{P}=10$ host plants with $n_{L}=6$ larvae at the start of the experiment. The boxes represent the median, and $25 \%$ and $75 \%$ percentiles. The whiskers extend to the maximum values, circle denotes an outlier. Different letters denote statistically significant differences $(P<0.05)$ between the groups.

The present study analyzed both the preference and the performance prediction of the plant vigor hypothesis and gives new support to this hypothesis and, more generally, to the preference-performance hypothesis (Jaenike, 1978). The results show that females of the monophagous leaf beetle $C$. canaliculata Laich. prefer to oviposit on large individuals of its host plant S. pratensis L. and the observed preference positively correlates with offspring (i.e. larval) performance: larvae of $C$. canaliculata had a significantly shorter development time on leaves of large $S$. pratensis plants in the laboratory. It is assumed that a faster development time is advantageous for the offspring. Possible advantages could be that a fast development might promote fitness in growing populations with overlapping generations, pupae might have priority in finding pupation sites, or males might achieve a higher mating success through a higher protandry. As these possible reasons are not the case in C. canaliculata, another advantage might be a higher chance of survival as predicted by the 'slow-growth-highmortality hypothesis' (Feeny, 1976; Williams, 1999). This hypothesis suggests that, as slow-growing larvae spend a longer time in the more vulnerable, early stages of development than fast-growing larvae, they may suffer greater mortality from natural enemies and other mortality factors (Price et al., 1980; Rhoades, 1983; Grossmueller \& Lederhouse, 1985; Loader \& Damman, 1991; Häggström \& Larsson, 1995; Benrey \& Denno, 1997). High developmental rates often correlate with high nutritional quality of the leaf material (Ohmart et al., 1985; Lindroth \& Hemming, 1990; Lindroth \& 
Bloomer, 1991; Obermaier \& Zwölfer, 1999). This was also the case in the present study. The percentage of total leaf nitrogen was significantly higher in leaves of large host plants compared with leaves of small host plants. There may be two extremes of coping with low quality food: (1) to have a constant development time and pupate at a lower than optimal weight, or (2) to opt for a prolonged development time to gain the optimal weight for pupation. In the case of $C$. canaliculata the second possibility seems to have been realized: there was no significant difference in pupal weight between the two treatment groups, but the larvae reared on leaves of small host plants ( $\mathrm{S}$ group) - which were of poor nutritive quality - had a significantly longer development time than larvae reared on leaves of large host plants ( $\mathrm{L}$ group). Contrary to this result, pupal development time was longer in the L group, yet total development time was still highly significantly shorter in the L group. Pupal development time may depend on the pupal weight or on the sex of the larvae. However, as already mentioned, there was no significant difference in pupal weight between the two treatment groups, neither was there any correlation between pupal weight and development time. As the sex ratio of the larvae was not recorded in the experiment, no conclusion can be drawn on this possible explanation.

According to the prediction of the slow-growth-high-mortality hypothesis (Feeny, 1976; Williams, 1999), a prolonged development time of larvae on leaves of small $S$. pratensis plants - as found in the laboratory - should lead to a higher mortality of larvae on small plants in the field. Indeed, the survival probability of larvae in the field was significantly higher on large than on small $S$. pratensis plants when all predators had free access to the plant. On plants where all predators were excluded there was no difference in survival between large and small host plants. However, development time in the field did not differ between larvae on small and on large plants. This may be due to the unstable weather conditions in the field compared with the constant setting in the climatic chamber where the developmental studies were conducted. The field conditions may consequently have led to a higher variability of larval time, which could have disguised any differences between larvae on large and small host plant individuals.

What could then explain the difference in mortality between the plant size groups? If survival is compared within the treatment groups, the only significant difference between large and small plants can be found in the No Cage group. Thus, at first sight one might think that the cages might have given protection from abiotic forces like wind and rain, resulting in a higher survival of the larvae. However, as the comparison within the plant size groups shows, there was no significant difference in survival between the No Cage and Open Cage group, which contradicts this first hypothesis. Thus, a more probable explanation is that large plants provide an enemy-free space (Jeffries \& Law- 
ton, 1984) for the larvae due to their size and their architectural complexity. As the larvae of $C$. canaliculata feed on the underside of the leaves of their host plant, they are not very conspicuous to predators. There are as yet no published studies on natural enemies of $C$. canaliculata, but it is reported that larvae of other tortoise beetles are predated by, for example, Coccinellid and Carabid beetles, Hemipteran bugs, ants, and spiders (Olmstead \& Denno, 1993). On large host plants, which mostly have a higher number of leaves than small plants, predators may have to search for a longer time to find the larvae. In support of this hypothesis, it has been reported that a high structural complexity of plant architecture has a negative influence on the searching efficiency of parasitoids (Andow \& Prokrym, 1990; Lukianchuk \& Smith, 1997; Gingras et al., 2002).

Another explanation for the loss of larvae could be that on small plants more larvae left the host plant to search for a higher quality plant. However, this hypothesis could not explain the observed pattern. If there were a difference in leaving tendency between small and large plants, this tendency should show in the Closed Cage group as well, because dispersing individuals would have been caught in the ring of glue before they reached the cage and might return to the plant. However, in the Closed Cage group (i.e. without any predator-caused mortality) there was no significant difference in larval survival between large and small plants, and only in two cases a single larva was found in the glue. Consequently there is no reason to assume a significant difference in leaving tendency between the plant size categories. On the other hand, there was a significant difference in larval survival between caged and uncaged experiments with small plants. It may therefore be concluded that the difference in larval survival on large and small host plants in the uncaged treatment group was due to predator-caused mortality. This would again favor the first explanation given here, assuming that the larvae can profit from an enemy-free space on large host plants.

Additionally, the results presented in this study give support to the "neural limitation hypothesis' (Levins, 1969). This theory predicts that neural constraints result in a trade-off between diet breadth and the ability to discriminate among hosts, i.e. specialized species should be more capable of choosing between host plants of different quality than generalists (Janz \& Nylin, 1997; Bernays, 1998, 2001). Thus, the ability of $C$. canaliculata - as a very specialized species - to choose host plants depending on quality meets the predictions of the neural limitation hypothesis.

Summing up the results, this study supports the performance prediction of the plant vigor hypothesis (Price, 1991) and therefore corroborates the preference-performance hypothesis (Jaenike, 1978). Larvae of the monophagous leaf beetle $C$. canaliculata performed better on large host plant individuals, which were also preferred as oviposition sites by female beetles. Larval development times were shorter on leaves of 
large plants in the laboratory. This could not be confirmed in the field; yet a higher proportion of larvae survived to pupation on large plants in the field. Further detailed information on predator- and non predator-caused mortality and on larvae that may possibly leave the plant are needed.

\section{ACKNOWLEDGEMENTS}

We are grateful to Thomas Hovestadt for statistical advice, to two anonymous referees for helpful comments on an earlier version of this manuscript, and to Elfriede Reisberg for the nitrogen analyses. The authors thank the government of Lower Franconia (Bavaria, Germany) for permission to work in the nature reserve. The study was financially supported through a scholarship granted by the Evangelisches Studienwerk e.V. Villigst.

\section{REFERENCES}

Andow, D. A. \& Prokrym, D. R. (1990). Plant structural complexity and host-finding by a parasitoid. Oecologia 82: 162-165. 10

Awmack, C. S. \& Leather, S. R. (2002). Host plant quality and fecundity in herbivorous insects. Annual Review of Entomology 47: 817-844. 2

Ballabeni, P., Wlodarczyk, M. \& Rahier, M. (2001). Does enemy-free space for eggs contribute to a leaf beetle's oviposition preference for a nutritionally inferior host plant? Functional Ecology 15: 318-324. 2

Benrey, B. \& Denno, R. F. (1997). The slow-growth-high-mortality hypothesis: a test using the cabbage butterfly. Ecology 78: 987-999. 8

Berdegué, M., Reitz, S. R. \& Trumble, J. T. (1998). Host plant selection and development in Spodoptera exigua: do mother and offspring know best? Entomologia Experimentalis et Applicata 89: 57-64. 2

Bernays, E. A. (1998). The value of being a resource specialist: Behavioral support for a neural hypothesis. American Naturalist 151: 451-464. 10

Bernays, E. A. (2001). Neural limitations in phytophagous insects: Implications for diet breadth and evolution of host affiliation. Annual Review of Entomology 46: 703-727. 10

Bernays, E. A. \& Chapman, R. F. (1994). Host-Plant Selection by Phytophagous Insects. Chapman and Hall, New York. 2

Björkman, C., Larsson, S. \& Bommarco, R. (1997). Oviposition preference in pine sawflies: a trade-off between larval growth and defence against natural enemies. Oikos 79: 45-52. 2

Courtney, S. P. \& Kibota, T. T. (1990). Mother doesn't know best: selection of hosts by ovipositing insects. In: Bernays, E. A. (ed.) Insect-Plant Interactions, vol. 2, CRC Press, Boca Raton, pp. 161-188. 2

Craig, T. P., Itami, J. K. \& Price, P. W. (1989). A strong relationship between oviposition preference and larval performance in a shoot-galling sawfly. Ecology 70: 1691-1699. 2

Craig, T. P. \& Ohgushi, T. (2002). Preference and performance are correlated in the spittlebug Aphrophora pectoralis on four species of willow. Ecological Entomology 27: 529-540. 2 
Crawley, M. J. (1989). Insect herbivores and plant population dynamics. Annual Review of Entomology 34: 531-564. 2

De Bruyn, L., Scheirs, J. \& Verhagen, R. (2002). Nutrient stress, host plant quality and herbivore performance of a leaf-mining fly on grass. Oecologia 130: 594-599. 2

Faria, M. L. \& Fernandes, G. W. (2001). Vigour of a dioecious shrub and attack by a galling herbivore. Ecological Entomology 26: 37-45. 2

Feeny, P. (1976). Plant apparency and chemical defense. In: Wallace, J. W. \& Mansell, R. L. (eds.) Biochemical Interactions between Plants and Insects (Recent Advances in Phytochemistry), vol. 10, Plenum Press, New York, pp. $1-40.8,9$

Forister, M. L. (2004). Oviposition preference and larval performance within a diverging lineage of lycaenid butterflies. Ecological Entomology 29: 264-272. 2

Fritz, R. S., Crabb, B. A. \& Hochwender, C. G. (2000). Preference and performance of a gall-inducing sawfly: a test of the plant vigor hypothesis. Oikos 89: 555-563. 2

Frohne, D. \& Jensen, U. (1985). Systematik des Planzenreichs (unter besonderer Berücksichtigung chemischer Merkmale und pflanzlicher Drogen). Fischer, Stuttgart. 4

Gingras, D., Dutilleul, P. \& Boivin, G. (2002). Modeling the impact of plant structure on host-finding behavior of parasitoids. Oecologia 130: 396-402. 10

Grossmueller, D. W. \& Lederhouse, R. C. (1985). Oviposition site selection: an aid to rapid growth and development in the tiger swallowtail butterfly, Papilio glaucus. Oecologia 66: 68-73. 8

Häggström, H. \& Larsson, S. (1995). Slow larval growth on a suboptimal willow results in high predation mortality in the leaf beetle Galerucella lineola. Oecologia 104: 308-315. 8

Hanley, J. A. \& McNeil, B. J. (1982). The meaning and use of the area under a receiver operating characteristic (ROC) curve. Radiology 143: 29-36. 5

Hanley, J. A. \& McNeil, B. J. (1983). A method of comparing the areas under receiver operating characteristic curves derived from the same cases. Radiology 148: 839-843. 5

Harris, M. O., Sandanayaka, M. \& Griffin, W. (2001). Oviposition preferences of the Hessian fly and their consequences for the survival and reproductive potential of offspring. Ecological Entomology 26: 473-486. 2

Hawkins, B. A., Thomas, M. B. \& Hochberg, M. E. (1993). Refuge theory and biological control. Science 262: 14291432. 2

Howlett, B. G., Clarke, A. R. \& Madden, J. L. (2001). The influence of leaf age on the oviposition preference of Chrysophtharta bimaculata (Olivier) and the establishment of neonates. Agricultural and Forest Entomology 3 : 121-127. 2

Jaenike, J. (1978). On optimal oviposition behavior in phytophagous insects. Theoretical Population Biology 14: 350356. $2,7,8,10$

Janz, N. \& Nylin, S. (1997). The role of female search behaviour in determining host plant range in plant feeding insects: a test of the information processing hypothesis. Proceedings of the Royal Society B: Biological Sciences 264: 701-707. 10

Jeffries, M. J. \& Lawton, J. H. (1984). Enemy free space and the structure of ecological communities. Biological Journal of the Linnean Society 23: 269-286. 9

Kouki, J. (1993). Female's preference for oviposition site and larval performance in the water lily beetle, Galerucella nymphaeae (Coleoptera: Chrysomelidae). Oecologia 93: 42-47. 2 
Krebs, J. R. \& Davies, N. B. (1997). Behavioural Ecology. Blackwell Science, Oxford. 2

Levins, R. (1969). Some demographic and genetic consequences of environmental heterogeneity for biological control. Bulletin of the Entomological Society of America 15: 237-240. 10

Lindroth, R. L. \& Bloomer, M. S. (1991). Biochemical ecology of the forest tent caterpillar: responses to dietary protein and phenolic glycosides. Oecologia 86: 408-413. 8

Lindroth, R. L. \& Hemming, J. D. C. (1990). Responses of the gypsy moth (Lepidoptera: Lymantriidae) to tremulacin, an aspen phenolic glycoside. Environmental Entomology 19: 842-847. 8

Loader, C. \& Damman, H. (1991). Nitrogen content of food plants and vulnerability of Pieris rapae to natural enemies. Ecology 72: 1586-1590. 8

Lukianchuk, J. L. \& Smith, S. M. (1997). Influence of plant structural complexity on the foraging success of Trichogramma minutum: a comparison of search on artificial and foliage models. Entomologia Experimentalis et Applicata 84: 221-228. 10

Mattson, W. J. (1980). Herbivory in relation to plant nitrogen content. Annual Review of Ecology and Systematics 11: 119-161. 2

Mayhew, P. J. (1997). Adaptive patterns of host-plant selection by phytophagous insects. Oikos 79: 417-428. 1, 7

McNeill, S. \& Southwood, T. R. E. (1978). The role of nitrogen in the development of insect/plant relationships. In: Harborne, J. B. \& Emden van, H. F. (eds.) Biochemical Aspects of Plant and Animal Coevolution, Biochemical aspects of plant and animal coevolution, Academic Press, London, pp. 77-98. 2

Nagelkerke, N. J. D. (1991). A note on the general definition of the coefficient of determination. Biometrika 78: 691-692. 5

Nylin, S. \& Janz, N. (1996). Host plant preferences in the comma butterfly (Polygonia c-album): do parents and offspring agree? Écoscience 3: 285-289. 2

Obermaier, E., Pfeiffer, B. \& Linsenmair, K. E. (2001). Mortality and parasitism in West African tortoise beetles (Coleoptera: Chrysomelidae). Entomologia Generalis 25: 189-203. 2

Obermaier, E. \& Zwölfer, H. (1999). Plant quality or quantity? Host exploitation strategies in three Chrysomelidae species associated with Asteraceae host plants. Entomologia Experimentalis et Applicata 92: 165-177. 2, 9

Ohmart, C. P., Stewart, L. G. \& Thomas, J. R. (1985). Effects of food quality, particularly nitrogen concentrations, of Eucalyptus blakelyi foliage on the growth of Paropsis atomaria larvae (Coleoptera: Chrysomelidae). Oecologia 65: 543-549. 8

Olmstead, K. L. \& Denno, R. F. (1993). Effectiveness of tortoise beetle larval shields against different predator species. Ecology 74: 1394-1405. 10

Preszler, R. W. \& Price, P. W. (1995). A test of plant-vigor, plant-stress, and plant-genotype effects on leaf-miner oviposition and performance. Oikos 74: 485-492. 2

Price, P. W. (1991). The plant vigor hypothesis and herbivore attack. Oikos 62: 244-251. 2, 7, 10

Price, P. W., Bouton, C. E., Gross, P., McPheron, B. A., Thompson, J. N. \& Weis, A. E. (1980). Interactions among three trophic levels: Influence of plants on interactions between insect herbivores and natural enemies. Annual Review of Ecology and Systematics 11: 41-65. 8

R Development Core Team (2004). R: A language and environment for statistical computing. R Foundation for Statistical Computing, Vienna, Austria, URL http://www.r-project.org. 5

Rausher, M. D. (1979). Larval habitat suitability and oviposition preference in three related butterflies. Ecology 60: 503-511. 2 
Rhoades, D. F. (1983). Herbivore population dynamics and plant chemistry. In: Denno, R. F. \& McClure, M. S. (eds.) Variable Plants and Herbivores in Natural and Managed Systems, Academic Press, New York, pp. 155-220. 8

Scheirs, J. \& De Bruyn, L. (2002). Integrating optimal foraging and optimal oviposition theory in plant-insect research. Oikos 96: 187-191. 2

Scheirs, J., De Bruyn, L. \& Verhagen, R. (2000). Optimization of adult performance determines host choice in a grass miner. Proceedings of the Royal Society B: Biological Sciences 267: 2065-2069. 2

Scheirs, J., Zoebisch, T. G., Schuster, D. J. \& de Bruyn, L. (2004). Optimal foraging shapes host preference of a polyphagous leafminer. Ecological Entomology 29: 375-379. 2

Schmeil, O. \& Fitschen, J. (1996). Flora von Deutschland und angrenzender Länder. Quelle \& Meyer, Wiesbaden. 3

Shiojiri, K. \& Takabayashi, J. (2003). Effects of specialist parasitoids on oviposition preference of phytophagous insects: encounter-dilution effects in a tritrophic interaction. Ecological Entomology 28: 573-578. 2

Singer, M. C. (1986). The definition and measurement of oviposition preference in plant-feeding insects. In: Miller, J. R. \& Miller, M. A. (eds.) Insect-Plant Interactions, Springer, New York, pp. 65-94. 1, 2

Singer, M. S. \& Stireman III, J. O. (2003). Does anti-parasitoid defense explain host-plant selection by a polyphagous caterpillar? Oikos 100: 554-562. 2

SPSS Inc. (2004). SPSS for Windows, Rel. 12.0.2. SPSS Inc., Chicago, Illinois. 5

Stephens, D. W. \& Krebs, J. R. (1986). Foraging Theory. Princeton University Press, Princeton. 2

Strong, D. R., Lawton, J. H. \& Southwood, T. R. E. (1984). Insects on Plants. Community Patterns and Mechanisms. Blackwell, London. 2

Trautner, J., Geigenmüller, K. \& Bense, U. (1989). Käfer beobachten, bestimmen. Neumann-Neudamm, Melsungen. 3

Underwood, D. L. A. (1994). Intraspecific variability in host plant quality and ovipositional preferences in Eucheira socialis (Lepidoptera: Pieridae). Ecological Entomology 19: 245-256. 2

Valladares, G. \& Lawton, J. H. (1991). Host-plant selection in the holly leaf-miner: does mother know best? Journal of Animal Ecology 60: 227-240. 2

van Nouhuys, S., Singer, M. C. \& Nieminen, M. (2003). Spatial and temporal patterns of caterpillar performance and the suitability of two host plant species. Ecological Entomology 28: 193-202. 2

White, T. C. R. (1993). The Inadequate Environment. Nitrogen and the Abundance of Animals. Springer, Berlin. 2

Williams, I. S. (1999). Slow growth, high mortality - a general hypothesis, or is it? Ecological Entomology 24: 490495. 8,9

Zweig, M. H. \& Campbell, G. (1993). Receiver-operating characteristic (ROC) plots: a fundamental tool in clinical medicine. Clinical Chemistry 39: 561-577. 5 